\title{
Peristiwa G 30 S sebagai Isu Kontroversial pada Mata Pelajaran Sejarah di SMA Kota Bima
}

\author{
Oleh : Edy Suparjan \\ Pendidikan Sejarah PPS UNJ
}

\begin{abstract}
This study aimed to describe the process of teaching history with event materials G $30 \mathrm{~S}$. This study implemented for three months housed in SMAN 2 and SMAN 4 Kota Bima. The method used is a qualitative method using analytical descriptive. Collecting data in this study using the method of observation, interviews and documentation. Sources of key data used in this research: key informant and the informant is vice principal core curriculum is a history teacher and student. Data were analyzed using analysis of Huberman Milles ie, data reduction, data presentation and then verify and pengambilam conclusions. The results showed that the learning G30S lasted less monotonous and attract students, the method used by the teacher has not varied, instructional media used was whiteboard reference books still use textbooks published by private simple. Besides infrastructure such as, Laptops, LCD, and VCD do not support learning activities in the classroom. The issue of revival of the PKI and government apology to the victim less of an effect on learning about the material G $30 S$ in school, especially in the city of Bima. This is because the curriculum is implemented using the curriculum in 2006.
\end{abstract}

Key words: Learning, G 30 S, Subjects History

\begin{abstract}
Abstrak
Penelitian ini bertujuan untuk mendeskripsikan proses pembelajaran sejarah dengan materi peristiwa G 30 S.penelitian ini di laksanakan selama tiga bulan bertempat di SMAN 2 dan SMAN 4 Kota Bima. Metode penelitian yang digunakan adalah metode kualitatif dengan menggunakan deskriptif analitis. Pengambilan data dalam penelitian ini menggunakan metode observasi, wawancara dan dokumentasi. Sumber data utama yang digunakan dalam penelitian ini: informan kunci yaitu wakasek Kurikulum dan informan inti yaitu guru sejarah dan siswa. Teknik analisis data menggunakan Analisis Milles Huberman yaitu, Reduksi data, penyajian data kemudian verifikasi dan pengambilam kesimpulan. Hasil penelitian menunjukan bahwa pembelajaran $G 30 \mathrm{~S}$ berlangsung monoton dan kurang menarik minat siswa, metode yang digunakan oleh guru belum bervariasi, media pembelajaran yang digunakan adalah papan white board buku sumber referensi masih menggunakan buku paket sederhana terbitan swasta. Selain itu sarana prasarana seperti, Laptop, LCD, dan VCD belum menunjang kegiatan pembelajaran di kelas. Isu kebangkitan PKI serta permintaan maaf pemerintah kepada korban, kurang berpengaruh terhadap proses pembelajaran mengenai materi G 30 S di sekolah khususnya di Kota Bima. Hal ini karena kurikulum yang diterapkan menggunakan kurikulum 2006.
\end{abstract}

Kata Kunci: sistem pendidikan, kurikulum sejarah, isi

\section{PENDAHULUAN}

Peristiwa Gerakan 30 September telah mengakar dalam benak masyarakat Indonesia, tidak terkecuali para pelajar, Mahasiswa sampai kalangan elit politik kalau mendengar kata G 30
S pasti melekatkan dengan kata PKI dibelakangnya. Hal tersebut tidak terlepas dari konstruksi dan sosialisasi yang cukup massif dilakukan oleh pemerintah Orde Baru, baik materi pelatihan maupun dalam kurikulum pendidikan. Yang 
paling kita ingat adalah buku putih yang diterbitkan oleh Sekretariat Negara Republik Indonesia.

Seiring berjalannya waktu, G 30 S menjadi wacana yang diperdebatkan. Pada kurikulum 2004 kata PKI sempat terhapus sehingga dalam teks hanya tertulis G $30 \mathrm{~S}$, hal tersebut membuat Kejaksaan Agung dan Kementrian Pendidikan dan Kebudayaan turun tangan dan menarik buku-buku tersebut yang telah terbit.

Akhir-akhir ini di media terdengar kemunculan kembali logo PKI, misalnya di kawasan pertokoan di Depok pedagang yang menjual Kaos PKI di tangkap oleh Kepolisian setempat. Kemudian pada tanggal 15 Agustus 2015 simbol-simbol PKI muncul di Pamekasan dan Jember beberapa orang warga membawa foto para tokoh PKI seperti Aidit dan Nyoto dalam rangka merayakan HUT RI yang ke- 70 .

Rabu malam, 29 September 2015 di TV One diadakan Debat terbuka dengan tema "50 Tahun G 30 S/PKI perlukah Negara minta maaf? " acara ini selenggarakan oleh Indonesian Lawyer Club. Beberapa nara sumber yang hadir antara lain, Ilham Aidit, Djoko Pekik, Fahmi Idris (Angkatan 66), A.M Fatwa (Angkatan 66), Kivlen Zen (TNI), Tjipta Lesmana, Firdaus Wajdhi, Marsudi Suhud (Ketua PBNU), Salim Said serta anak dari Jenderal Ahmad Yani. Dalam kesempatan tersebut Lesmana menyatakan, "kalau PKI menyuruh negara minta maaf, berarti negara yang salah, lalu bagaimana PKI yang membantai tentara, pemuda Ansor, HMI dan Muhammadiyah".

Menurut Imron Cotan menyatakan, bahwa akan lebih bermartabat jika kita mampu melihat dalam prespektif yang berbeda, yaitu permintaan maaf yang akan dikeluarkan oleh Presiden RI dimaksudkan dan dirancang ditujukan kepada seluruh masyarakat Indonesia sebagai bentuk rasa tanggungjawabnya karena telah gagal menjalankan kewajiban konstitusi melindungi hak hidup rakyatnya.

Persoalan negara minta maaf atau tidak, jangan dipermasalahkan, karena tidak semestinya semua dosa masa lalu pemerintah yang dahulu juga ditanggung sepenuhnya oleh pemerintah sekarang. Menurut penulis, kalau pemerintah minta maaf berarti secara langsung pemerintah telah melegiitimasi bahwa ideologi komunisme itu benar dan PKI tidak pernah melakukan kesalahan. Lalu bagaimana dengan TAP MPR/XXV/1966 tentang larangan Marxisme, Leninisme dan sejenisnya.

Di Madiun terjadi demonstrasi besarbesaran pada Rabu, 30 September 2015, demo dilakukan oleh beberapa organisasi yang tergabung dalam perkumpulan Gerakan Bela Negara diantara organisasi yang hadir adalah Kesatuan Aksi Mahasiswa Muslim Indonesia (KAMMI), Himpunan Mahasiswa Islam (HMI), KAHMI, Pelajar Islam Indonesia (PII), BEM di berbagai fakultas berbagai perguruan tinggi, Pemuda Muhammadiyah, dan sejumlah LSM. Selain orasi yang menyebutkan, tidak ada tempat bagi komunis di NKRI", selain itu di tulis dalam Baliho "Ganyang PKI, Tegakkan Pancasila...", PKI No.....Pancasila Yes, NKRI Harga Mati. Dalam pernyataan sikap, diantaranya GBN meminta DPR, MPR dan pemerintah mempertahankan TAP MPRS No XXV tahun 1966 tentang larangan Ajaran Marxisme/Leninisme dalam segala bentuk. Laksanakan Undangundang Nomor 27 Tahun 1999 tentang keamanan negara dengan melarang penyebaran ajaran komunisme. 
Pasca Orde Baru tafsir mengenai G 30 S bermunculan berbagai Prespektif dikemukakan. mulai tafsir bahwa G 30 $S$ adalah konflik internal angkatan darat sampai keterlibatan pihak Asing dalam prahara 1965 yang menanam luka sangat lama dalam benak bangsa Indonesia. Namun, yang sangat aneh adalah tafsir tentang keterlibatan Soeharto dalam G 30 S tidak dijelaskan dalam kurikulum 2013, ada apa ?. bukankah ini adalah sebuah pembohongan publik dan diskriminasi terhadap tokoh lain yang terlibat dalam G $30 \mathrm{~S}$.

Berdasarkan hasil observasi awal peneliti diSMAN 4 Kota Bima, ditemukan bahwa guru sejarah masih menggunakan buku referensi yang ada disekolah, guru masih mengajar dengan metode ceramah, masih menjelaskan dengan versi pemerintah dengan PKI sebagai dalang tunggal dalam peristiwa tersebut. Guru masih kekurangan sumber referensi dalam melaksanakan tugasnya sebagai guru sejarah. Siswa kurang menyenangi pembelajaran sejarah karena metode dan media yang digunakan guru sejarah kurang bervariasi.

Fakta yang terjadi di sekolah bahwa guru masih menjelaskan G $30 \mathrm{~S}$ dalam versi tunggal PKI sebagai dalang dari peristiwa tersebut. Pandangan semacam ini justru akan membosankan dan tidak menantang kreatifitas siswa. Padahal tujuan utama pendidikan sejarah di tingkat SMA adalah agar siswa berpikir kritis, kreatif dan Inovatif. Jadi, dalam materi G $30 \mathrm{~S}$ sebagai materi yang kontroversial dapat merangsang siswa untuk berpikir kritis, terkait semua versi yang dijelaskan oleh guru di kelas.

Berdasarkan karakteristik permasalahan tersebut, maka peneliti tertarik untuk melakukan penelitian dengan judul "Pembelajaran G 30 S sebagai isu kontroversial pada mata pelajaran sejarah".Adapun alasan memilih 2 sekolah, karena peneliti ingin membandingkan antara pemahaman guru SMA yang satu dengan pemahaman Guru SMA lainnya. Selain itu peneliti, ingin melihat bagaimana $G 30$ S diajarkan oleh guru di kelas, apakah Isu nasional tentang PKI akan mempengaruhi cara mengajar guru-guru sejarah yang ada di daerah lebih khususnya di Kota Bima. Setelah adanya penelitian ini, diharapkan guru sejarah dapat mengajarkan materi G 30 S dengan berbagai versi sebagaimana yang ada dalam kurikulum 2013.

Sulasman mengatakan Sejarah adalah topik yang sangat menarik tidak hanya itu, sejarah juga mengajarkan hal-hal yang sangat penting, terutama keberhasilan dan kegagalan para pemimpin serta sistem perekonomian yang pernah ada, bentuk pemerintahan, dan hal penting lainnya.

Susanto menjelaskan bahwa ada tiga prinsip yang perlu diperhatikan dalam pembelajaran sejarah, yaitu:

a) Pembelajaran yang dilakukan haruslah adaptif terhadap perkembangan siswa dan perkembangan zaman

b) Pembelajaran sejarah hendaklah berorientasi pada pendekatan nilai

c) Strategi pembelajaran yang digunakan hendaklah tidak mematikan kreatifitas dan memaksa siswa hanya untuk menghafal fakta dalam buku teks.

Hasil wawancara Detak dengan Mayor TNI (Purn) Soekarbi Wakil Komandan Bataliyon 530/Para/Brawijaya, menyatakan bahwa yang memerintahkan pasukan Brawijaya agar menghadiri HUT ABRI yang akan diselenggarakan pada tanggal 5 Oktober adalah Pangkostrad 
Mayjen Soeharto. Hal tersebut dapat dilihat Radiogram nomor 220 dan nomor 239 tanggal 21 September 1965. Isinya perintah agar Yon 530/Para Brigader 3/ Brawijaya dipersiapkan dalm rangka HUT ABRI ke 20 tanggal 5 Oktober 1965 di Jakarta dengan perlengkapan tempur garis pertama.

Menurut Warman Adam, Subandrio menyimpulkan rangkaian peristiwa dari 1 Oktober sampai 11 Maret 1966 sebagai kudeta merangkak yang dilakukan melalui empat tahap. Tahap pertama, menyingkirkan saingannya di Angkatan Darat seperti Yani dan lain-lain. Tahap kedua, membubarkan PKI yang merupakan rival terberat tentara sampai saat itu. Tahap ketiga, melemahkan kekuatan pendukung Bung Karno dengan menangkap 15 Mentri yang Soekarnois, termasuk Soebandrio. Tahap keempat, mengambil alih kekuasaan dari Presiden Soekarno.

Menurut Riana, Pemberontakan G 30 S/PKI diibaratkan Perang Bharata Yudha merupakan perang konspirasi. Riana menyimbolkan Presiden Soekarno sebagai Raja Duryudana, Waperdam I Soebandrio sebagai Pendeta Durno, Sangkuni disimbolkan sebagai DN Aidit yang suka memberikan intrikintrik kepada Raja Duryudana, Letkol Untung sebagai Algojo, Mayjen Soeharto di simbolkan sebagai Yudhistira yang akan menggantikan Raja Duryudana, Jenderal Nasution di simbolkan sebagai Sri Kreshna yang memberikan nasehat kepada Yudhistira. Kemudian Kolonel Sarwo Edhi Wibowo layaknya Sang Bima dan Arjuna disimbolkan sebagai Umar Wirahadikusuma.

Tentang G 30 S Iwan menambahkan "teori lain adalah: Coup untung Cs ini cuma semacam peristiwa pembakaran
Reichstag saja...yang justru disuruh dan biayai oleh Hitler sendiri". Hal ini juga bisa kita analisis kembali mengenai kesaksian Bambang Widjanarko, yang menuduh Presiden Soekarno terlibat dalam skenario besar untuk menculik Jenderal, dengan menyuruh Letkol Untung ketika diadakan Musyawarah Teknik di Senayan.

Sementara Salim Haji Said mengenai peristiwa G $30 \mathrm{~S}$ merupakan peristiwa penculikan Jenderal Ahmad Yani dan kawan-kawannya lebih kepada pendaulatan. Artinya, diculik untuk didaulat melepaskan posisi pimpinan Angkatan Darat.

Kemudian dalam dokumen nomor 179 tertanggal 2 Desember 1965, isi telegram tersebut, menyatakan kesiapan memberikan bantuan kepada Adam Malik senilai Rp. 50 juta untuk operasi penggayangan Gerakan 30 September. Isi telegram tersebut diperkuat lagi oleh pernyataan McAvoy yang mengatakan, ia kenal Adam Malik karena diperantarai oleh Shigetada Nishijima, dan Adam malik meminta uang 50 juta untuk membiayai gerakan KAP-Gestapu.

Dari berbagai teori diatas, setelah peneliti mengurai kembali G $30 \mathrm{~S}$ bahwa peristiwa tersebut merupakan sebuah konspirasi akbar dua kubu dalam politik 1965, Pertama, adalah konspirasi ketua PKI D.N Aidit bersama Biro Khusus dalam hal ini Syam beserta perwira bawahan yang tidak puas terhadap pola kehidupan atasannya yang serba mewah sementara perwira rendahan dalam keadaan ekonomi yang kurang. Kedua, Konspirasi akbar Mayjen Soeharto bersama perwira intelejennya beserta bantuan dan keterlibatan Amerika dalam hal ini adalah CIA. Karena nafsu politik D.N Aidit tidak mampu lagi dikendalikan, ia pun secara tergesa-gesa mengutus Biro Khusus 
untuk melakukan penculikan terhadap Dewan Jenderal. Hal ini, membuat kubu Soeharto berpeluang untuk menuduh PKI yang melakukan makar terhadap kekuasaan Soekarno. dan setelah melihat kondisi politik yang kacau, kubu Soeharto pun berambisi untuk mengambil alih kekuasaan, hal tersebut diperkuat dengan di keluarkannya Surat Perintah 11 Maret 1966. Jadi kegagalan aksi penculikan yang dilakukan oleh Biro Khusus, telah memberikan legitimasi kepada Mayjen Soeharto untuk menumpas PKI sekaligus mengambil alih kekuasaan dari tangan Presiden Soekarno.

\section{METODOLOGI PENELITIAN}

Penelitian ini menggunakan pendekatan kualitatif, melalui metode deskriptif analisis. Penelitian ini menggunakan data yang berkaitan dengan proses pembelajaran terhadap Materi G $30 \mathrm{~S}$. pengambilan data dalam penelitian ini menggunakan instrumen pedoman Observasi, pedoman wawancara dan dokumentasi.

Penelitian ini dilakukan di SMAN 2 dan SMAN 4 Kota Bima. Subjek dalam penelitian ini adalah Guru dan Siswa, sasaran penelitian yaitu proses pembelajaran dengan materi G $30 \mathrm{~S}$ di kelas XII IPS.

Kemudian dari data yang didapatkan peneliti melakukan analisis data dengan model Miles and Huberman sebagai berikut :

1. Pengumpulan data; proses ini di lakukan dari awal hingga akhir penelitian di lakukan.

2. Reduksi Data; proses pemilihan, pemusatan perhatian pada penyederhanaan, pengabstrakan, membuat rangkuman yang inti lalu menyusunnya dalam satuan-satuan yang disebut kategorisasi.

3. Penyajian data; dilakukan dalam bentuk uraian singkat, bagan, hubungan antar kategori atau teks yang bersifat naratif.

4. Kesimpulan atau verifikasi data; proses ini akan memberikan kesimpulan apakah penelitian yang dilakukan telah sesuai atau konsisten dan menjawab rumusan masalah yang telah ditentukan.

\section{HASIL PENELITIAN DAN PEMBAHASAN}

\section{Peran Guru dalam Pembelajaran G $30 \mathrm{~S}$}

Pada umumnya pembelajaran sejarah di SMA Negeri 2 dan SMA Negeri 4 Kota Bima masih menerapkan Kurikulum 2006 atau yang lebih dikenal dengan Kurikulum KTSP. Adapun peran guru dalam mengelola proses pembelajaran di kelas adalah sebagai berikut.

Paparan data mengenai peran guru dalam pembelajaran Gerakan 30 September 1965 di SMA adalah perencanaan guru dalam RPP, pelaksanaan kegiatan pembelajaran G $30 \mathrm{~S}$ dan evaluasi dalam pembelajaran G $30 \mathrm{~S}$.

Guru dalam menjelaskan materi G 30 S di SMAN 2 Kota Bima masih sangat monoton dan guru masih sangat mendominasi dalam pembelajaran. Hal tersebut dapat terlihat ketika pembelajaran berlangsung, setelah duduk mengabsen siswa, Ibu Nursiah kemudian berdiri menjelaskan materi di depan siswa, lalu sambil jalan di tengah siswa. Pada umumnya guru hanya menggunakan metode ceramah, kemudian pemberian tugas, hanya berputar pada kedua metode tersebut. 
Ditinjau dalam Rencana Pelaksanaan Pembelajaran (RPP) yang dibuat oleh guru, waktu yang digunakan dalam pembelajaran G 30 S/PKI setiap pertemuan $3 \times 45$ menit tersebut, metode yang digunakan adalah pendekatan model ICT, life skill dan pemberian tugas. Namun, yang diterapkan guru di kelas justru metode ceramah dan pemberian tugas. (lihat lampiran RPP)

Pelaksanaan pembelajaran materi Peristiwa Gerakan 30 September 1965/PKI sebagaimana yang tercantum dalam RPP guru melakukan Apersepsi membuka pelajaran dan menyuruh peserta didik berdo'a.Namun guru tidak menjelaskan tujuan pembelajaran. Kemudian dalam pemanfaatan sumber belajar, guru sama sekali tidak memiliki kreatifitas dalam mengkoleksi serta menambahkan sumber referensi untuk dijadikan bahan dan sumber belajar, kecuali buku paket Sejarah yang ada di Perpustakaan.

Sumber belajar yang di cantumkan oleh guru dalam RPP kelas XII mencatumkan beberapa sumber belajar antara lain buku sumber sejarah SMA XII IPS ESIS, Peta Konsep, Power point, OHP, buku-buku penunjang yang relevan dan internet. Namun pada kenyataannya beberapa sumber yang digunakan tidak muncul pada saat proses pembelajaran berlangsung, seperti Peta Konsep, Power point, OHP dan Internet. Sumber belajar yang digunakan hanya buku paket terbitan Global.

Berdasarkan hasil wawancara peneliti dengan Ibu Nursiah yang menyatakan, "Saya tidak begitu banyak pakai metode karena siswa sudah dewasa, metode yang biasa saya pakai adalah informasi.Metode informasi ini, sebenarnya diterapkan di Kurikulum 2013.Namun saya lebih memilih metode tersebut walaupun dalam buku paket masih diterapkan KTSP". (Hasil Wawancara, Rabu, 24 Februari 2016).

Kemudian hasil Observasi dan wawancara peneliti dengan Pak Burhan selaku Guru Sejarah kelas XII di SMAN 4 Kota Bima, dalam melaksanakan kegiatan pembelajaran menggunakan buku Sejarah karangan Rini Mardikaningsih dan R. Sumaryanto yang masih berpedoman pada Kurikulum Tahun 2006.Sementara, Ibu Nursiah selaku guru sejarah kelas XII di SMAN 2 Kota Bima dalam pelaksanaan pembelajaran menggunakan buku sumber sejarah karangan M. Habib Mustopo dkk terbitan Yudhistira yang juga masih berpedoman pada KTSP.

Terkait penggunaan media pembelajaran. Dalam proses pembelajaran di kelas Ibu Nursiah masih menggunakan media tradisional atau media papan tulis untuk membantu meringkas dan menulis soal. Hal ini Berdasarkan hasil wawancara peneliti dengan Ibu Nursiah selaku guru sejarah kelas XII di SMAN 2 yang menyatakan, " Saya sudah siapkan Laptop, tetapi kendalanya di sekolah ini tidak ada LCD nya. Sehingga saya hanya menggunakan media gambar untuk menjelaskan materi G 30 S." (Hasil Wawancara, Rabu, 24 Februari 2016)

Dokumen bahan ajar yang dipakai oleh guru menggunakan buku paket Sejarah 3 untuk kelas XII SMA Program IPS karangan Habib Mustopo dkk. Berdasarkan hasil wawancara dengan Ibu Nursiah mengatakan, "dalam mengajarkan G 30 S saya menggunakan buku paket dan LKS, itu yang membantu saya.Tentunya buku paket tersebut berdasarkan kurikulum 2006. Karena di sekolah kami masih diterapkan Kurikulum KTSP", (Hasil wawancara, Rabu, 24 Februari 2016). 
Kondisi pembelajaran materi G $30 \mathrm{~S}$ yang diajarkan oleh Ibu Nursiah di kelas XII IPS 1 sudah cukup kondusif, karena ada interaksi antara guru dan siswa, selain itu siswa-siswa yang aktif bertanya dan mengisi soal yang diberikan oleh Ibu Nursiah. Sementara di kelas XII IPS 2 pembelajaran G 30 S kurang mendapatkan perhatian siswa terlebih lagi di kelas XII IPS 3 pembelajaran G 30 S kurang di senangi siswa sehingga mempengaruhi kondisi kelas menjadi brisik dan tidak kondusif.

Hasil wawancara dengan Pak Burhan selaku guru kelas XII di SMAN 4 Kota Bima mengatakan, "dalam mengajarkan G 30 S saya menggunakan buku paket I Wayan Badrika dan buku-buku terbitan Yudhistira". (Hasil Wawancara, Selasa, 23 Februari 2016). Terkait dengan metode pembelajaran yang digunakan dalam pembelajaran G 30 S. Pak Burhan menjelaskan bahwa "mengenai pendekatan dan metode saya selalu menggunakan metode ceramah, dialog dan pemberian tugas, pendekatan dialog ini dimaksudkan agar siswa interaktif sehingga kelas menjadi hidup". (Hasil wawancara, Selasa, 23Februari 2016).

\section{Materi G 30 S di sekolah}

Proses pembelajaran G 30 S yang dijelaskan oleh Ibu Nursiah di kelas XII IPS 1 berlangsung cukup kondusif walau pun masih ada beberapa siswa yang kurang memperhatikan penjelasan dari Ibu Nursiah. Namun di kelas ini siswanya saling berebutan jika ada soal yang diberikan oleh ibu guru.

Berbeda dengan di kelas XII IPS 3 pembelajaran di mulai pukul 11.45 wita, kondisi siang hari sangat mempengaruhi situasi kelas sehingga proses pembelajaran G 30 S di kelas ini tidak terkontrol dengan baik, Ibu Nursiah menjelaskan materi G $30 \mathrm{~S}$ dari demokrasi liberal sampai pada penculikan beberapa perwira angkatan darat, kondisi kelas sangat tidak kondusif, sesekali Ibu Nursiah menegur siswa dengan berkata, dengan berkata, "anakanak tolong perhatikan di depan, tolong jangan brisik". Siswa pun diam sejenak dan kembali mendengarkan penjelasan dari Ibu Nursiah.

Sementara Pak Burhan memiliki cara yang berbeda dengan Bu Nursiah dalam menjelaskan materi pelajaran di kelas, Pak Burhan yang dalam menjelaskan materi lebih sering menggunakan metode ceramah dan pemberian tugas dengan menggunakan media papan tulis dan sumber belajar buku yang digunakan oleh siswa ditambah dengan buku karangan I Wayan Badrika yang merupakan buku yang menjadi pegangan Pak Burhan dalam mengajar. Dalam proses pembelajaran G $30 \mathrm{~S}$ yang terlihat oleh peneliti, interaksi antara guru dan siswa terlihat sangat bagus, kecuali di kelas XII IPS 2.

Di kelas XII IPS 1 Pak Burhan menjelaskan kondisi Indonesia pada jaman demokrasi terpimpin, Partai PKI mendapaturutan 4 besar pada pemilu 1955, kemudian menjelaskan pembentukan Biro khusus pada tahun 1964 oleh D.N Aidit. Sampai ke penjelasan penculikan beberapa Jenderal yang dipimpin oleh Letkol Untung.

Baik Drs Burhan maupun Dra. Hj Nursiah dalam pelaksanaan pembelajaran sejarah menjelaskan G30S dalam satu versi yaitu G 30 S sebagai dalang tunggal dan pelaku kudeta tahun 1965. Hal tersebut sesuai dengan tuntutan Kurikulum 2006.

Terkait cara guru mengajarkan materi G 30 S yang kontroversi, sebagaimana pernyataan Pak Burhan yang menyatakan, 
"kalau saya melihat dari kacamata sejarah kudeta yang dilakukan oleh Soeharto. Namun saya berusaha berada ditengahtengah dan melihat proses G 30 S. Sebagai proses yang konstitusional seperti keluarnya supersemar itukan diikuti TAP MPRS. Ada juga yang menganggap antara Sukarno dan PKI kan memilki hubungan yang sangat dekat. Kondisi negara pada saat itu sudah emergency, inilah yang memunculkan opini dalam masyarakat seolah-olah Sukarno teman dekatnya PKI bahkan orang PKI.

Kalau negara dibuat berlarut-larut seperti itu, sangat membahayakan kondisi negara. Dan hal ini dipengaruhi oleh PKI. Kondisi negara yang aman pun bisa dibuat kacau oleh PKI.Karena memang PKI sudah dua kali melakukan pemberontakan yaitu tahun 1948 dan 1965.Dalam waktu satu tahun yaitu tahun 1950 PKI Bangkit. Tahun 1951 D.N. Aidit terpilih menjadi ketua PKI.Kemudian pada tahun 1955 PKI mendapat 4 besar dalam pemilihan umum di bawah PNI, NU dan Masyumi.Setelah itu melakukan infiltrasi di tubuh TNI. Kemudian merasa kuat dan dengan cepat mencoba melakukan kudeta yang kita kenal dengan G 30 S/PKI tahun 1965, dan pada akhirnya gagal". (Hasil wawancara, Selasa, 23 Februari 2016).

Kemudian komponen yang paling penting dalam proses pembelajaran adalah evaluasi. Evaluasi merupakan cara guru atau sekolah dalam mengkomunikasikan program kepada publik, menyediakan informasi bagi pembuat keputusan serta penyempurnaan program yang ada. Evaluasi yang dilakukan oleh Ibu Nursiah selaku Guru sejarah kelas XII di SMAN 2 Kota Bima merupakan cara evaluasi biasa yaitu dengan memberikan soal esay di akhir penjelasan materi, tujuan evaluasi ini adalah untuk mengetahui nilai kognitif siswa saat itu. Sedikit berbeda dengan Ibu Nursiah, Pak Burhan selaku guru sejarah kelas XII di SMAN 4 Kota Bima dalam melaksanakan evaluasi terhadap siswa, Pak Burhan memberikan soal latihan sebanyak 15 nomor untuk pilihan ganda dan 5 nomor untuk esay di kelas XII IPS 1. Sementara di kelas XII IPS 2 dan IPS 3 hanya diberikan soal esay masing-masing 5 nomor.

\section{Faktor- faktor yang mempengaruhi keterlaksanaan pembelajaran $G 30 \mathrm{~S}$}

Terkait dengan faktor yang
mempengaruhi pembelajaran G30S diSMA. Ada beberapa point yang peneliti temukan antara lain. 1) Siswa kurang hobi mempelajari sejarah lebih khususnya materi G 30 S, 2).Kesiapan guru dalam menggunakan Teknologi berbasis Informatika masih terbatas, 3) Sarana seperti LCD, Laptop dan Sumber Referensi untuk bahan ajar masih kurang, seperti buku-buku koleksi di perpustakaan, buku pegangan guru hanya mengandalkan buku-buku terbitan swasta.

Berdasarkan hasil wawancara peneliti dengan guru SMAN 2 Kota Bima yang menyatakan " saya sudah siapkan Laptop, tetapi kendalanya di sekolah ini tidak ada LCD nya. Sehingga saya hanya menggunakan media gambar untuk menjelaskan materi G 30 S." (Hasil wawancara Rabu, 24 Februari 2016)

Selain itu, Pak Burhan juga mengatakan, kendalanya ada, siswa ketika saya menjelaskan materi ada yang ngantuk. Main Hp, kemudian dalam hal media saya menggunakan media papan tulis untuk menulis kata-kata yang sulit dipahami oleh siswa. banyak sekali faktornya, terutama dalam media dan alat bantu seperti Laptop dan LCD. Sebenarnya 
saya ingin menayangkan film G 30 S/PKI agar di tonton oleh siswa setelah itu saya menjelaskan.Namun itu tidak di dukung dengan sarana yang memadai, buku paket juga, masih kurang di perpustakaan kadang siswa satu buku di baca berdua. Kemudian dalam kenyamanan dalam kelas siswa sering mengeluh kepanasan, disebabkan oleh ruangan tidak memiliki kipas angin. (Hasil Wawancara, Selasa, 23Februari 2016).

Mengenai faktor-faktor yang
keterlaksanaan
pempengaruhi
siswa dengan serius. Hal ini dapat
perhatikan hasil wawancara peneliti
dengan siswa-siswa sebagai berikut.

Berdasarkan wawancara peneliti dengan Ferdiansyah menyatakan, "terkadang gurunya suka marah-marah, kalau kita bertanya balik, guru tersebut bilang apa kalian gak dengar apa? yang ibu jelaskan dari tadi". Guru suka marah, karena kelas ini sangat sedikit yang mau belajar, terkadang ada yang tidur, ada juga yang main Hp sendiri".

“Terkait dalam proses pembelajaran, kami ingin ada media seperti yang biasa dipakai oleh anak-anak bahasa inggris, pakai media layar ditayangkan, karena kalau tidak seperti itu, kami kebanyakan tidak mendengar suara ibu guru, dan materinya jarang diulangi, sehingga kami cepat lupa. Jujur kami sangat bosan dengan cara mengajar guru yang ceramah dan bercerita terus". (Hasil wawancara, Rabu, 2 Maret 2016).

Kemudian hasil wawancara peneliti dengan Ariansyah Ramadhon siswa SMAN 2 kelas XII IPS 1 yang menyatakan, "Kami kebanyakan tidak mendengar suara ibu guru, dan materinya jarang diulangi, sehingga kami cepat lupa. Jujur kami sangat bosan dengan cara mengajar guru yang ceramah dan bercerita terus. Selain itu, tidak menggunakan media seperti power point seperti anak-anak Bahasa Inggris pakai media pada saat pembelajaran hanya jurusan IPS yang tidak menggunakan media semacam itu". (Hasil Wawancara, Rabu, 9 Maret 2016).

Tanggapan siswa terkait faktor yang mempengaruhi keterlaksanaan pembelajaran G 30 S pada intinya hampir sama, seperti yang ungkapkan oleh Maulana siswa SMAN 2 kelas XII IPS 3. Maulana mengatakan bahwa, "terkadang gurunya suka marah-marah, kalau kita bertanya balik, guru tersebut bilang, "apa kalian gak dengar apa yang ibu jelaskan dari tadi". Guru suka marah, karena kelas ini sangat sedikit yang mau belajar, terkadang ada yang tidur, ada juga yang main Hp sendiri. Kemungkinan kalau Ibu Guru menggunakan powerpoint, atau media film, dapat mengurangi rasa bosan kami dalam mengikuti proses pembelajaran sejarah". (Hasil Wawancara, Rabu, 16 Maret 2016 )

\section{KESIMPULAN DAN REKOMENDASI}

\section{KESIMPULAN}

Peran guru dalam pembelajaran G 30 $S$ kurang variatif dan sangat kaku.Dalam merancang dan merumuskan perangkat pembelajaran guru hanya mengambil dari internet, Rencana pembelajaran tersebut tidak dimodifikasi oleh guru. Sehingga dalam Rencana Pembelajaran tidak sesuai dengan apa yang diterapkan oleh guru di kelas. Buku sumber yang dipakai oleh Guru SMAN 2 dan SMAN 4 Kota Bima masih mengikuti pedoman kurikulum 2006. Metode pembelajaran yang digunakan pada kedua sekolah metode ceramah, tanya jawab serta pemberian tugas. Begitu juga dengan 
Media pembelajaran antara kedua sekolah menggunakan media papan white board dengan buku paket sederhana.Guru kurang dalam mengoperasikan Laptop, Sekolah belum menyediakan LCD bagi para guru sejarah.

Baik SMAN 2 maupun SMAN 4 Kota Bima respon siswa terhadap materi G $30 \mathrm{~S}$ kurang positif, terlihat siswa malas belajar, siswa kurang menanyakan hal-hal seputar kontroversinya G 30 S. bahkan siswa juga tidak menggunakan internet dalam mempelajari materi G 30 S. sehingga pembelajaran monoton mendengarkan Ceramah guru di kelas.

Terkait dengan faktor yang mempengaruhi keterlaksanaan materi G 30 S di kelas. Ada beberapa poin yang peneliti temukan antara lain :

1. Siswa kurang menyenangi sejarah lebih khususnya materi G $30 \mathrm{~S}$, siswa ada yang tidur dalam kelas, siswa ada yang main HP sendiri, siswa cepat lupa dan bosan.

2. Cara mengajar guru yang monoton kurang bervariasi, guru suka marahmarah, tidak mengulangi materi pembelajaran, Kesiapan guru dalam menggunakan teknologi berbasis informatika masih terbatas.

3. Sarana seperti LCD, VCD, Laptop dan Sumber Referensi untuk bahan ajar masih kurang, seperti bukubuku koleksi di perpustakaan, buku pegangan guru hanya mengandalkan buku-buku terbitan swasta.

4. Implementasi Kurikulum yang masih tidak konsisten sehingga berpengaruh terhadap kesiapan guru dalam mengajar.

\section{REKOMENDASI}

Berdasarkan hasil penelitian di lapangan, peneliti memberikan saran berupa :

1. Bagi pemerintah, khususnya kementrian pendidikan nasional, agar melakukan pelatihan yang serius bagi guru-guru sejarah terhadap perubahan kurikulum, sehingga tidak ada lagi guru yang menyatakan tidak siap terhadap perubahan kurikulum

2. Bagi guru sejarah, agar terus meningkatkan kompetensi, memperbanyak sumber-sumber pengetahuan, baik dengan cara memperbanyak referensi untuk dibaca dan memperbanyak metode yang bervariatif yang disesuaikan dengan kemajuan dan perkembangan ilmu pengetahuan, kemudian menggunakan media-media yang sesuai dengan materi ajar serta disesuaikan dengan kemajuan jaman, intinya menggunakan teknologi yang ada. Selain itu, guru dalam menjelaskan peristiwa G $30 \mathrm{~S}$ selayaknya mulai menjelaskan materi G 30 S berbagai versi sebagaimana yang ada dalam buku sejarah kelas XII kurikulum 2013.

3. Bagi sekolah, khususnya SMAN 2 dan SMAN 4 Kota Bima agar menyediakan sarana dan prasarana yang menunjang dan mendukung keterlaksanaan pembelajaran sejarah, seperti Laptop. LCD, Proyektor dan benda-benda replika sejarah. Dalam hal implementasi kurikulum sekolah seharusnya melaksanakan kurikulum 2013 apapun resikonya, bukan menjalankan kurikulum 2006.

4. Bagi peneliti selanjutnya, diharapkan bagi peneliti selanjutnya agar memperluas penelitian sampai ke isu- 
isu kontroversial lainnya, sehingga memperkaya data dan sumber yang diperlukan di kemudian hari.

\section{DAFTAR PUSTAKA}

Adam, Asvi Warman. 1965 Orang-orang Dibalik Tragedi, Yogyakarta: Galang Press. 2009.

Heri, Susanto.Seputar Pembelajaran Sejarah, Isu, Gagasan dan Strategi Pembelajaran,Yogyakarta: CV. Aswaja Presindo, 2014..

Kementerian Pendidikan dan Kebudayaan. Sejarah Indonesia: Buku Guru / Kementerian Pendidikan dan Kebudayaan, Jakarta: Kementerian Pendidikan dan Kebudayaan, 2014.

Guru Kesulitan Jawab soal, Kompas, Rabu, 11 November 2015.

Pribadi, Benny. A. Model Assure Untuk Mendesain Pembelajaran Sukses,Jakarta: Dian Rakyat, 2011.

Putra, Nusa. Penelitian Kualitaif: Proses dan Aplikasi, Jakarta : Indeks, 2011.

Riana, I Ketut. Misteri Angka Dibalik Kegagalan Pemberontakan G 30 S/PKI Prespektif Budaya. Jakarta : Pusat Analisis dan Kajian Transformasi Sosial, 2007.

Said, Salim Haji. Gestapu 65 PKI, Aidit, Sukarno dan Soeharto. Bandung: Mizan. 2015.

Sastrapratedja, M. Pendidikan Belum Transformatif, Jakarta: Kompas, 29 Mei 2015

Satori. Djam'an \& Aan Komariah. Metodologi Penelitian Kualitatif, Bandung: Alfabeta. 2010

Simatupang, Iwan. Tragedi G-30-S dalam bayang-bayang Bung Karno sang peragu, Jakarta: Insan Merdeka, 2013.

Sugiyono.Metode Penelitian Pendidikan Pendekatan Kuantitatif, Kualitatif, dan RED, Bandung:Alfabeta, 2010.
Suharsimi, Arikunto.Prosedur Penelitian Suatu Pendekatan Praktik, Jakarta: Rineka Cipta, 2006.

Sulasman. Metodologi Penelitian Sejarah, Bandung: Pustaka Setia, 2014.

Suyanto dan Asep Jihad. Guru Profesional: Strategi Meningkatkan Kualifikasi dan Kualitas Guru di Era Global, Esensi Erlangga Group, 2013.

Tim Liputan Khusus 1965. Jejak CIA Pada Tragedi 1965, Jakarta: Tempo, Edisi 5-11 Oktober 2015. 